\title{
Temporal and trophic partitioning promote coexistence between mesocarnivores in a Mediterranean landscape
}

\author{
Iago Ferreiro-Arias $^{1}{ }^{*}$ Jorge Isla $^{1}$, Pedro Jordano $^{1}$, Ana Benítez-López ${ }^{1}$ \\ ${ }^{1}$ Department of Integrative Ecology, Estación Biológica de Doñana, Consejo Superior de \\ Investigaciones Científicas, Avda. Américo Vespucio, 26, 41092, Sevilla, Spain.
}

*Corresponding author. email: iago.ferreiro.arias@gmail.com

Iago Ferreiro-Arias - ORCID: 0000-0003-4178-5783

Pedro Jordano - ORCID: 0000-0003-2142-9116

Jorge Isla - ORCID: 0000-0002-2307-9730

Ana Benítez-López - ORCID: 0000-0002-6432-1837 


\section{Abstract}

2 1. The partition of the ecological niche can enhance the coexistence of predators due to

3 differences in how they exploit three main resources: food, space, and time, the latter being

4 an axis that often remains unexplored.

5 2. We studied niche segregation in a Mediterranean mesocarnivore community in sites where

6 the top predator, the Iberian lynx, is absent, addressing simultaneously two niche axes: the

$7 \quad$ temporal and the trophic axes.

8 3. Temporal overlap between prey and predator and between potential competitors was

9 analysed by comparing daily activity patterns of predators and prey species through data

10 obtained by using 24 camera-traps deployed in three different sites of the Doñana National

11 Park. We further examined the trophic dimension by compiling and analysing diet

12 information in the study area and exploring trophic preferences between potential

13 competitors.

14 4. We found an overall temporal segregation between trophic generalist species while those

15 species which showed higher values of temporal overlap differ largely in their trophic

16 preferences. Furthermore, we observed an overall high degree of overlap between the activity

17 patterns of predators and their putative prey (the common genet vs small mammals and the

18 red fox vs European rabbit).

19 5. Our study suggests that coexistence of the different species that compose the

20 mesocarnivore assemblage in Mediterranean landscapes can be facilitated by the marked

21 temporal segregation between generalist species, but also by differences in trophic

22 preferences by specialist species when their activity patterns overlap with other 
23 mesocarnivores. Our findings reinforce that idea that the coexistence mechanisms underlying

24 community structure are multidimensional.

\section{Keywords}

26 Diel activity, Doñana, Genetta genetta, Herpestes ichneumon, interspecific competition,

27 Meles meles, niche differentiation, Vulpes vulpes.

\section{Introduction}

Understanding the mechanisms that promote coexistence of species with similar

30 ecological requirements is a central topic in community ecology, where competitive

31 interactions between species have the potential to affect diversity patterns by limiting or

32 promoting coexistence (Chesson, 2000). In order to mitigate the negative impact of

33 interspecific competition, species often partition resources along three main niche dimensions

34 (temporal, trophic and spatial), which eventually result in niche differentiation (Schoener,

35 1974). Most studies concerning species coexistence focus on the differential use of habitat

36 and food resources; nonetheless, the differential use of the diel cycle may enhance

37 coexistence of same-sized species, particularly among predator species (Di Bitetti et. al.,

38 2009; Wang \& Fisher, 2012).

Diel activity patterns are cyclical behavioural patterns which can be influenced by

40 several factors (i.e., prey availability or thermoregulatory strategies) (Lode, 1995; Maloney

41 et. al., 2005). Within mammals, a large variability and plasticity in their activity patterns has

42 been documented (Bennie et al. 2014). This diversity of diel cycles could be due to the plastic

43 nature of behavioural responses to different pressures, which may in turn induce marked

44 variations in daily rhythms among different scenarios (Ensing et al., 2014; Gaynor et. al.,

45 2018). Broadly, activity patterns displayed by mammals are determined by circadian 
46 endogenous boundaries (Kronfeld-Schor \& Dayan, 2003), which, particularly in carnivores,

47 are shaped by external factors (Monterroso et.al., 2014; Zielinski, 1986), and thus their diel

48 cycle use is context-dependent. Hence, the co-occurrence of species that compete for a certain

49 resource has the potential to produce shifts in the daily activity patterns of competitively

50 surrogate species. For example, crab-eating and pampas foxes have been reported to change

51 their daily foraging activity in sympatric areas where both species are present (switching

52 from diurnal to nocturnal), compared to allopatric areas where only one fox species is present

53 (Di Bitetti et al., 2009).

In addition, predators' activity patterns could also adjust their daily activity rhythms to

those hours of the day in which the availability of prey increases (Foster et al., 2013), while,

at the same time, prey species could generate a temporal mismatch by centering their activity

57 at times when there is a lower risk of predation (Fenn \& Macdonald, 1995). Consequently,

58 high temporal overlap between carnivores and their putative prey have been reported in some

59 predator-prey systems (Linkie \& Ridout, 2011), whereas in others an asynchrony was found

60 in their respective activity peaks (Arias-Del Razo et al., 2011; Díaz $\square$ Ruiz et al., 2016). As a

61 consequence, the daily activity of a given predator could be a result of a cost-benefit trade-off

62 between maximizing their activity during periods with high prey availability (benefit) but

63 also higher mortality risk due to encounters with intraguild competitors (cost) (Santos et al.,

64 2019).

Interspecific interactions play an important role in structuring a mammalian

community (Holt et al., 1994), especially in carnivores where competition not only arises as a

67 consequence of exploiting the same resource simultaneously, but also due to the risk

68 associated with intraguild predation. Intraguild predation (IGP) is an antagonistic interaction 
70 (Palomares \& Caro, 1999; Polis et.al., 1989), being specially reported on top-predators

71 against surrogate competitors (Palomares \& Caro, 1999). The IGP's effects in competitors

72 can be diverse, from abundance reductions and distributional shifts (in space and time)

73 (Jiménez et al., 2019; Newsome et al., 2017) to behavioural modifications through restriction

74 of their activity patterns (Wang \& Fisher, 2012). Because apex predators play a key role in

75 ecosystem functioning due to their regulatory role on populations of prey and medium-sized

76 carnivores (top-down control), their extinction frequently triggers cascading effects through

77 direct and indirect interactions among trophic levels (Terborgh et. al., 2010). Hence, the

78 collapse of top predators can lead to an eventual increase of the distribution and abundance of

79 medium-sized carnivore populations, a phenomenon coined 'mesopredator release' by Soulé

80 et al. (1988) that has been repeatedly documented (Prugh et al., 2009; Brashares et. al., 2010).

81 In the Iberian Peninsula, the Iberian lynx (Lynx pardinus) exerts its role as a top-

82 predator on the populations of surrogate competitors (Palomares et. al., 1998; Palomares

83 et.al., 1996). Sizeable reductions of mesocarnivore abundance have been reported after the

84 reintroduction of the Iberian lynx (Jiménez et al., 2019), reinforcing the idea that the

85 coexistence between these carnivores is supported by spatial structuring, where the

86 probability of occurrence of the lynx is negatively associated with the presence of

87 mesopredators (Monterroso et.al., 2020; Palomares et al., 1996). In Doñana National Park,

88 the carnivore guild is composed by a habitat and trophic specialist top predator (the Iberian

89 lynx, Lynx pardinus) and mesocarnivores such as the red fox (Vulpes vulpes), the European

90 badger (Meles meles) and the Egyptian mongoose (Herpestes ichneumon), which are

91 characterized by a wide niche breadth in terms of habitat and trophic preferences. This

92 assemblage is completed by the common genet (Genetta genetta), with a considerably

93 narrower diet. The negative effects that the Iberian lynx has on these mesocarnivores occur

94 mainly through intraguild predation, particularly on Egyptian mongooses (Egyptian 
mongoose), common genets (Genetta genetta) and red foxes (Vulpes vulpes) (Palomares et al.

110 of a top-predator, focusing on the temporal segregation of four mesocarnivore species: the red

111 fox (Vulpes vulpes), the European badger (Meles meles), the common genet (Genetta

112 genetta), and the Egyptian mongoose (Herpestes ichneumon). Thus, this study aims: 1) to

113 explore the relationship between mesocarnivores along the trophic niche axis; 2) to determine

114 the diel activity patterns of predator and prey species and their synchrony; and 3) to quantify

115 the temporal overlap or segregation between potential competitors. Following a niche

116 partitioning conceptual framework, we hypothesize that there would be greater temporal

117 segregation in those species that have a higher degree of overlap in their respective trophic

118 niches, while species that have similar use of the diel cycle would show differentiated trophic 
119 preferences in order to promote coexistence by reducing competition along temporal or

120 trophic niche axes.

\section{$121 \quad$ Material and methods}

\section{Study area}

This study was carried out in Doñana National Park $\left(37^{\circ} 1^{\prime} \mathrm{N}, 6^{\circ} 33^{\prime} \mathrm{W}\right)$ in three 1 -ha

124 sites characterized by juniper stands (Juniperus phoenicea subsp. turbinata) of different age

125 and ecological succession stages, ranging from mature stands with a higher degree of

126 vegetation cover to an advance front of juniper stands with lower vegetation cover. "Sabinar

127 del Marqués" (SABMAR) constitutes the most mature stage with 10520 junipers/ha,

128 "Sabinar del Ojillo" (SABOJI) is at an intermediate stage with 9010 junipers/ha, and

129 "Sabinar de Colonización" (SABCOL) represents the colonization front stage with 2030

130 junipers/ha (Supplementary Fig. S1).

\section{Data collection}

We deployed eight camera traps per site that were rotated periodically through 35

randomly selected focal juniper plants. Juniper plants were selected at random in each of five

subplots within each of the three main sites, with the subplots distributed regularly

throughout the main plot. The structure of this habitat consists of paths of variable width

between juniper individuals, where the cameras were installed at 1-m height focusing on the

137 ground and the bottom of the plant. Camera trap models employed in this study were

138 Browning Dark Ops Pro XD and Bushnell Aggressor. Camera traps were active for ca. 10

139 days in each of these rotations and then changed to other 8 locations, thus ensuring that the

140 whole site was sampled in 5 weeks. Following this procedure, we obtained data from a total 
141 set of 24 camera traps sampling the three sites during two campaigns: October 2018 - May

1422019 and October 2019 - June 2020. No attractants were used over the two years of sampling.

143 The diel activity cycle of each species was characterized by pooling the total number

144 of detections across all cameras during the whole study period. In order to avoid data

145 dependency, we discarded consecutive detections of a given species within a site (Davis,

146 Kelly, \& Stauffer, 2011; Monterroso et al., 2014). When multiple photographs of the same

147 species were taken within a 15-min interval, we considered them as a single capture event to

148 ensure capture independence. Since the area covered by our study sites is limited (ca. 1

$149 \mathrm{ha} /$ site), we deem $15 \mathrm{~min}$ a reasonable time period for a species to abandon the site. In cases

150 where a given individual was detected repeatedly without leaving the camera detection zone,

151 only the time of its first detection was considered. In our analyses we used either the total,

152 absolute number of records per species (e.g., to compare the relative frequency of sunrise,

153 day, dusk, and nocturnal records within a given site) or the relative frequency of records

154 expressed as number of photographs per species per camera-day (e.g., when comparing

155 across sites that received different sampling intensity).

157 National Park namely the Egyptian mongoose, the red fox, the European badger and the

158 common genet (Valverde, 1967), and their respective prey species. Large top predators such

159 as the wolf (Canis lupus) and the Iberian lynx (Lynx pardinus) were not present in our study

160 sites. Potential prey species include lagomorphs (mainly European rabbits, Oryctolagus

161 cuniculus), small mammals and birds such as the red partridge Alectoris rufa. Detections

162 from ungulates (mainly Cervus elaphus and Sus scrofa) were not included in the analysis as

163 their presence in mesocarnivore diets is frequently associated with carrion consumption, with

164 direct predation being recorded sporadically on very young individuals (Valverde, 1967). 
165 Conversely, we did not have sufficient detections from the other lagomorph present in RBD

166 (Lepus granatensis, $\mathrm{N}=3$ ) to include them in this study.

\section{Trophic overlap data}

We searched on Web of Science (WOS) and Google Scholar for studies that reported

trophic preferences of the four mesocarnivores in Doñana National Park using the following

performing the search. We also gathered diet data for the common genet by consulting

experts (P. Ferreras). The selection of studies contains all the trophic information available

for the four species at different locations in the Doñana National Park and reflects the entire

trophic spectra of each of the different species (Supplementary Table S1). We collected all

food items per species and study without pooling seasons or periods in order to capture the

natural variability in dietary composition across the whole Doñana study area and its marked seasonal component.

Some studies reported information collected in previous studies (e.g., Martín et al.

(1995) and Fedriani et al. (1998), or Palomares and Delibes (1991b) and Palomares (1993)).

To avoid pseudo-replication issues, we kept only those studies where the data strictly belong

to different samples and periods. From each study, period and species, we extracted the

187 in an ordination of the studies corresponding to each mesopredator species based on their

188 similarity of prey species composition. We used the coordinates on the first two CA axes 
189 corresponding to each diet study to build convex polygons spanning each mesopredator group

190 of studies. Convex polygons illustrate the range of dietary variation shown by each

191 mesopredator species in relation to the diet composition of other species.

\section{Camera trap data analysis}

We extracted time and date from each detection of every camera trap in order to estimate daily activity patterns and temporal overlap between mesocarnivores and their potential prey, and between mesocarnivore potential competitors. As time and dates are variables with a circular nature, diel activity cycles were estimated using non-parametric

197 Kernel density plots, which provide a density function of the daily activity pattern of a given species (Rowcliffe et al., 2014). Raw data were subsampled in order to carry out analyses only for those species with more than 10 detections (Fisher, 1995). used by van Schaik and Griffiths (1996) by which species are classified according to the number of independent detections obtained as: diurnal (> $90 \%$ of the detections occurring during the daylight), nocturnal (> 90\% of the detections obtained at night), crepuscular (> $90 \%$ of their detections occur at dawn or dusk) or cathemeral if their activity pattern is distributed uniformly throughout the daily cycle. We tested whether the target species actually show a certain activity pattern and deviate from a random pattern using the Rao detection to another and induce bias to our results. Species could adjust their daily activity

210 levels depending on the day length, thus not taking this aspect into account when dealing with

211 strictly diurnal or nocturnal species could lead to the misinterpretation of the results and the

212 underestimation of peaks of daily activity (Vazquez et al., 2019). Therefore, we carried out a 
213 double average anchoring time transformation to take into account the mean average sunrise

214 and sunset times for the study area (Vazquez et al., 2019).

215 We evaluated the extent of temporal segregation between mesopredators using the

216 overlap coefficient $(\Delta)$ described by Ridout and Linkie (2009). This coefficient ranges from 0

217 to 1 , where 0 values represent completely different diel activity patterns while 1 represents

218 the maximum overlap between both species. Following Ridout and Linkie (2009), we used $\Delta_{1}$

219 for cases with a sample size lower than 75 detections, and $\Delta_{4}$ when sample size was equal or 220 greater than 75 detections.

Once the overlap coefficients between the different species were estimated, 99\%

confidence intervals were calculated through smoothed bootstrap analysis with 10,000

replicates. Moreover, we evaluated differences in pairwise comparisons of daily activity

Further, we used percentiles to establish threshold levels of overlap. Thus, $\Delta>75$ th percentile

moderate levels of overlap (Monterroso et al. 2014).

All analyses were conducted in R Studio 1.2.5033 Statistical Software (R Core Team,

2020). The correspondence analysis (CA) was carried out with "FactoMineR" package (Lê,

Josse, \& Husson, 2008); kernel density functions, overlap coefficients $(\Delta)$ and their

234 (Agostinelli \& Lund, 2017). Finally, we calculated mean average sunrise and sunset times 235 and performed the average anchoring transformation with the "activity" package (Rowcliffe, 


\section{Results}

The first two dimensions of the correspondence analysis explained $62 \%$ of the

241 variability of mesocarnivore diets (Fig. 1). Axis 1, which explained $34.5 \%$ of the variation,

242 clearly discriminates the trophic preferences of the European badger and the common genet

243 due to their eminently omnivorous and carnivorous diets, respectively, but not from the rest

244 of the mesocarnivores. The red fox and the European badger showed very close values due to

245 their frugivorous behaviour and the predominant consumption of lagomorphs and

246 invertebrates. Meanwhile, the Egyptian mongoose had the wider trophic preferences, with an

247 intermediate position between the omnivorous diets of the European badger and the red fox,

248 and the carnivorous diet of the common genet. Simultaneously, axis 2, which explained

$24927.3 \%$ of the trophic variation, is generated by variation between the diets of the red fox and

250 the common genet, with the latter preferring small mammals followed by birds as main food

251 items. However, the second dimension of the correspondence analysis does not discern

252 between the trophic niches of the red fox, the European badger and the Egyptian mongoose,

253 indicating that there is a greater trophic overlap between these three species with respect to

254 the common genet. Further, convex polygons indicate the ampler trophic diversification of

255 the generalist species (red fox, European badger and Egyptian mongoose) whose range of

256 prey types tends to be considerably wider compared with the common genet (Fig. 1).

\section{Species detections and diel activity patterns}

258 Results obtained in this study come from a total of 531 effective sampling days. All 
260 (number of days): $x \square \pm \mathrm{SD}=80.3 \pm 28.3 \mathrm{~d}$ for SABCOL; $80.4 \pm 27.3 \mathrm{~d}$ for SABOJI and

$26186.8 \pm 26.0 \mathrm{~d}$ for SABMAR. Broadly, 2786 detections in total were obtained throughout the

262 study period, of which 96 (3.44\%) could not be identified at the species level. Among all

263 detections, $16 \%$ corresponded to mesocarnivores, $28.7 \%$ to prey species, $15 \%$ to ungulates

264 and $38.7 \%$ to passeriformes, which were not included in this study (Supplementary Table

265 S2).

266

Regarding our target species, we recorded 301 detections of the red fox, with $54.8 \%$

267 of them in SABCOL and the rest of the detections evenly distributed between the other two

268 sites (SABOJI: 23.9\%; SABMAR: 21,3\%). A large amount of the detections obtained from

269 this species were linked to its nocturnal habits while the rest were distributed throughout

270 daylight periods, demonstrating a cathemeral activity pattern with a tendency towards

271 bimodality $(\mathrm{U}=142.26$; p-value < 0.05) (Supplementary Table S3). Conversely, detections of

272 European badgers were very scarce in the three study sites (total: 22 detections), with $77 \%$ of

273 the detections occurring at night and the rest during the dawn or dusk periods $(\mathrm{U}=178.95$; $\mathrm{p}$ -

274 value $<0.01)$. As for the common genet, its activity pattern was strictly nocturnal (95\% of the

275 records produced during nighttime; $\mathrm{U}=165.81$; $\mathrm{p}$-value $<0.01$ ), with most detections

276 occurring in SABCOL (62\% of detections). Finally, detections of Egyptian mongooses were

277 mainly concentrated in the SABOJI (61\%) while the other two sites maintained the same

278 proportion of records (ca. 20\%), showing a marked diurnal activity pattern in each of them

279 (92\% of the detections occurred during daylight; $\mathrm{U}=199.78 ; \mathrm{p}$-value < 0.01) (Supplementary

280 Table S3).

For prey species, most of the detections belonged to the European rabbit $(\mathrm{N}=650$

282 detections). Rabbit detections concentrated similarly between SABOJI and SABMAR, while

283 SABCOL had only 6 detections during the entire sampling period (Supplementary Table S2). 
284 Overall, the distribution of rabbit detections spanned throughout the day, with distinct activity

285 peaks around sunrise and sunset $(\mathrm{U}=156.97$; p-value $<0.01)$ (Supplementary Table S3).

286 Small mammals (Mus spretus and Apodemus sylvaticus) were detected 98 times,

287 mainly in SABMAR and only during nighttime $(\mathrm{U}=198.27$; $\mathrm{p}$-value $<0.01)$. Finally, red-

288 legged partridges were mostly detected in SABCOL (89\% of detections) and showed a

289 markedly diurnal activity pattern $(\mathrm{U}=226.53$; p-value < 0.01) (Supplementary Table S3).

predators and the potential prey items in the study area. The European rabbit showed a high degree of overlap with the red fox $\left(\Delta_{4}=0.84\right)$, followed by a moderate overlap with the

294 European badger $\left(\Delta_{1}=0.62\right)$. Conversely, both the common genet and the Egyptian

mongoose showed low overlap coefficients $\left(\Delta_{1}=0.47\right.$ and $\Delta_{1}=0.44$, respectively $)$ with rabbit activity patterns (Fi. 2).

We found a high temporal overlap between the activity patterns of small mammals 
307 availability. The red fox showed a predominantly nocturnal activity in SABCOL, where

308 rabbits were absent, and a tendency towards bimodal activity patterns in SABOJI and

309 SABMAR. Red fox activity patterns differed significantly between SABCOL and SABMAR

$310(\mathrm{~W}=11.14 ; \mathrm{p}$-value $<0.01)$, while no differences were found between SABCOL - SABOJI

$311(\mathrm{~W}=3.97$; $\mathrm{p}$-value $=0.137)$ or SABOJI - SABMAR $(\mathrm{W}=2.44$, $\mathrm{p}$-value $=0.295)$. In turn, no

312 statistically significant differences were found between activity patterns of the Egyptian

313 mongoose between SABCOL - SABOJI ( $\mathrm{W}=1.09$; $\mathrm{p}$-value $=0.58)$, SABCOL - SABMAR

$314(\mathrm{~W}=2.06 ; \mathrm{p}$-value $=0.36)$ and SABOJI - SABMAR $(\mathrm{W}=0.40 ; \mathrm{p}$-value $=0.82)($ Fig. 3$)$. The

315 temporal overlap between the activity patterns of the European rabbit and the red fox was $\Delta_{1}$

$316=0.79$ for SABOJI and $\Delta_{1}=0.73$ for SABMAR, while the temporal overlap between

317 European rabbit and Egyptian mongoose was sensibly lower $\left(\Delta_{1}=0.49\right.$ for $\mathrm{SABOJI}$ and $\Delta_{1}=$

3180.37 for SABMAR) (Fig. 3).

319 Temporal overlap and segregation between mesocarnivores

The average overlap and standard deviation of the activity patterns of the different

species was $\Delta_{1}=0.48$ and $\mathrm{SD}=0.29$, which reflect a low, although variable, temporal

overlap among these potential competitors. The average overlap values $\left(\Delta_{1} \pm \mathrm{SD}\right)$ of a species

with respect to the set of potential competitors were: $0.59 \pm 0.15$ for the fox; $0.57 \pm 0.34$ for

the badger; $0.50 \pm 0.36$ for the genet and $0.24 \pm 0.18$ for the Egyptian mongoose. 
331 segregation with the common genet $\left(\Delta_{1}=0.57 ; \mathrm{W}=24.96\right.$; $\mathrm{p}$-value $\left.<0.01\right)$ and the European

332 badger $\left(\Delta_{1}=0.71 ; \mathrm{W}=8.44 ; \mathrm{p}\right.$-value $\left.=0.014\right)$ and a low overlap with the Egyptian

333 mongoose $\left(\Delta_{1}=0.44 ; \mathrm{W}=73.48 ; \mathrm{p}\right.$-value < 0.01) (Fig. 4). Among study sites, temporal

334 overlap between the red fox and the Egyptian mongoose was $\Delta_{1}=0.41$ for SABCOL, $\Delta_{1}=$

3350.45 for SABOJI and $\Delta_{1}=0.36$ for SABMAR (Fig. 3).

\section{Discussion}

In this study we explore the mechanisms underlying the structure of Mediterranean

mesocarnivore communities living in sympatry in a mesopredator release scenario. We show

that mesocarnivore coexistence could be mediated by temporal or trophic segregation when

340 there is a greater overlap in any of these two niche axes. Unlike previous studies which have

341 been traditionally focused on spatial responses (Fedriani et al. 1999, Soto and Palomares

342 2015, Monterroso et al. 2020, but see Barrull et al. 2014, Monterroso et al. 2014, Vilella et al.

343 2020), our study provides new insights on the importance of temporal segregation at

344 facilitating co-occurrence by reducing resource overlap. Overall, we found a moderate level

345 of temporal segregation within the mesocarnivore guild in our study area, which was

346 composed by two strictly nocturnal species - the European badger and the common genet

347 (Camps, 2008; Palomares \& Delibes, 1994; Rodríguez et al., 1996), one diurnal - the

348 Egyptian mongoose (Palomares \& Delibes, 1992) and one with plasticity in its daily activity

349 pattern - the red fox, which ranges from diurnal (Cavallini \& Lovari, 1994) to nocturnal

350 habits (Baker et al., 2007). 
355 all species of rodents and insectivores, but it is certainly a specialized predator on Apodemus

356 sylvaticus when this prey is available (Palomares \& Delibes, 1991a; Virgós et al., 1999).

357 According to the Optimal Foraging Theory (MacArthur \& Pianka, 1966), predators maximize

358 its prey intake by showing an efficient foraging pattern. In the case of predators with

359 specialized diets such as the genet, they optimize their foraging behaviour by maximizing

360 synchrony of their daily activity patterns to their main and most profitable prey (Pyke et al.,

361 1977), as shown by our results. However, this pattern would not be so marked in predators

362 whose feeding behaviour is opportunistic and depends on the availability and accessibility of

363 several prey types (Pyke et al., 1977), which is the case for the rest of the mesocarnivores

364 studied.

The three other species that constitute the Doñana mesocarnivore assemblage are

366 known for their generalist feeding habits (Fedriani et al., 1999; Palomares, 1993; Rau, 1987).

367 Yet, we found trophic segregation of the Egyptian mongoose with respect to the red fox and

368 the European badger, with plant material (e.g., fleshy fruits) virtually absent from its diet.

369 Meanwhile, the trophic overlap between European badger and red fox was the highest within

370 the mesocarnivore community due to their omnivorous behaviour based on the consumption

371 of fleshy fruits, invertebrates and lagomorphs. Despite their reduced differences in terms of

372 spatial and trophic niche, these species showed a marked temporal segregation, displaying

373 distinct activity patterns: nocturnal, cathemeral and diurnal, which could ease coexistence by

374 exploiting similar resources at different times and thus reducing intraguild antagonistic

375 encounters.

376 The ecological plasticity and the ample spectra of resource use shown by these species

377 in their trophic and habitat niche axes suggest a scenario with potentially reduced

378 interspecific competition (Fedriani et al., 1999; Monterroso et al., 2020; Palomares, 1993). 
379 However, the temporal segregation of these species may become more relevant in situations

380 where those two niche axes exhibit ample overlap. For example, a reduction in the abundance

381 and availability of its main trophic resources at a given moment may lead to increasing

382 competition for the consumption of available secondary resources. A clear example is the

383 reported reduction in the consumption of European rabbits after a sudden population collapse

384 due to the emergence of the rabbit hemorrhagic disease (RHD) (Ferreras et. al., 2011), which

385 resulted in an increased trophic overlap among most generalist carnivore species. In such

386 cases, time partitioning becomes the main mechanism to facilitate coexistence by reducing

387 competitive stress in resource use among these species (Barrientos \& Virgós, 2006).

The European rabbit in the study area accounts for a very high percentage of the diet

400 Monzón et al., 2004). The colonization site (SABCOL) represents a Mediterranean scrubland

401 in an early ecological stage composed mainly by a low-density population of $J$. phoenicea

402 (2030 junipers/ha) and therefore, a low vegetation cover which does not fulfil rabbit habitat 
404 mature vegetation and high vegetation cover, which may serve as refuge for rabbits. In these

405 two sites, we found differences between the diel cycle use of rabbits, showing two activity

406 peaks in SABOJI and only one crepuscular activity peak in SABMAR. sites where the rabbit was present, putatively to match the activity patterns of this prey and

410 thus increase the probability of encounter. This was particularly obvious in SABOJI, where

411 the temporal overlap between fox activity and that of the rabbits was the highest. Yet, this

412 strategy was less beneficial in SABMAR, where an increase in the red fox activity around

413 dawn may have triggered an anti-predatory behaviour in the European rabbit, which

414 displayed only one activity peak at twilight, thus leading to low temporal overlap. This

415 observation is in line with the Risk Allocation Hypothesis by which a temporal mismatch

416 between activity patterns of a prey species and its predator could be due to a higher

417 perception of mortality risk that drives anti-predatory behaviours along the time axis (Lima \&

418 Bednekoff, 1999). Previous studies with Black-tailed jackrabbit (Lepus californicus), desert

419 cottontail (Sylvilagus audubonii) and the coyote (Canis latrans), have shown that lagomorphs

420 are able to shift their activity in order to reduce predation risk by the coyote (Arias-Del Razo

421 et al., 2011).

424 rabbit is a profitable prey for the generalist mesopredators in Doñana (Ferreras et al., 2011;

425 Martín et al., 1995; Palomares \& Delibes, 1991b; Fedriani, 1996), each predator displays

426 different hunting and consumption strategies of this prey item. Egyptian mongooses and

427 European badgers are species that preferentially consume younger rabbits by digging in 
428 burrows (Martín et al., 1995; Palomares \& Delibes, 1991b). Conversely, the red fox resorts to

429 a foraging strategy based mainly on the pursuit of prey items, although it also excavates in

430 rabbit burrows (Fedriani et al., 1999). Thus, these distinct foraging strategies could explain

431 why the Egyptian mongoose and European badgers display temporal asynchrony with the

432 prey's activity patterns while the red fox is expected to track and match the activity pattern of 433 its prey.

Hence, our study addresses for the first time the interspecific relationships among the

435 four mesocarnivores species present in Donana National Park by integrating together the

436 different patterns of daily activity and their respective overlap, as well their trophic ecologies.

437 Yet, these results should be taken with caution as the observational nature of this study does

438 not allow us to establish a clear causal relationship in the observed patterns of the different

439 species (i.e., temporal avoidance between competitors). Future research should address

440 variations in the relative abundance of mesopredators across sites with different rabbit

441 availability. Unfortunately, our sample size was limited to address these questions and we

442 recommend complementing camera trap data with other census methods (i.e. pellet counts or

443 track surveys). Complementarily, trophic relationships between potential competitors could

444 be evaluated by studying the diet composition through the collection, identification and

445 analysis of faecal samples in the different study sites.

$446 \quad$ Conclusions

447 The activity patterns of the different mesopredators are ultimately restricted by the

448 circadian boundaries, but at the same time can be slightly modulated by interspecific

449 interactions with both prey and potential competitors. Our results show that the coexistence

450 of the different species that compose the mesocarnivore assemblage in the Doñana National

451 Park can be facilitated by the temporal segregation among generalist species due to a 
452 divergence in the activity patterns (nocturnal, diurnal and cathemeral) but also by differences

453 in trophic preferences among specialist species, as suggested in previous studies (Fedriani et

454 al., 1999; Palomares \& Delibes, 1991c; Soto \& Palomares, 2015)

455 Our study further suggests that in order to clarify the coexistence mechanisms underlying

456 community structure, it is necessary to consider a multidimensional perspective, addressing

457 simultaneously multiple axes of the ecological niche. In markedly seasonal habitats like

458 Doñana, with patchy vegetation including ample gradients of vegetation cover and

459 successional status, even subtle differences in daily activity such as those documented here

460 represent multiple pathways to facilitate sympatry of coexisting mesopredator species. These

461 mechanisms might prove crucial for coexistence in settings where the apex predator is absent

462 and medium-sized carnivores live at high densities and show resource overlap. Recent

463 scenarios of rewilding with top predators may represent ideal conditions to experimentally

464 examine the effects of mesopredator release in diverse carnivore guilds like those of the

465 Mediterranean habitats studied here.

\section{Acknowledgements}

467 We thank J.P. González-Varó, T. Burgos, E. Quintero, C. Gutierrez, R. Tarifa and J.L.

468 Molina for technical support regarding species identification. We also thank P. Ferreras for

469 sharing his trophic data with us. I. Mendoza and B. Arroyo gave helpful comments on early

470 versions of the manuscript. Our work was funded by the project DISPMULTLAYER

471 (CGL2017-82847-P), Spanish Ministry of Science and Innovation (PJ). JI was supported by

472 the FPI grant PRE2018-085916 from the Spanish Ministry of Science and Innovation. ABL

473 was supported by a Juan de la Cierva-Incorporación grant (IJCI-2017-31419), Spanish

474 Ministry of Science, Innovation and Universities. We appreciate the support from ICTS-RBD

475 facilities during fieldwork. 


\section{Author contributions}

477 ABL conceived the original idea; IF collected the diet data, performed the analyses, designed 478 the figures and wrote the first draft of the manuscript; JI and PJ designed the methodology; JI 479 and IF compiled the camera-trap data. All authors contributed to the writing of the 480 manuscript.

\section{$481 \quad$ Data accessibility}

482 Data and R codes used in this study are deposited in GitHub

483 (https://github.com/IagoFerreiroArias/TempPart)

\section{References} (version 0.4-93). CA: Department of Environmental Sciences, Informatics and Statistics, Ca’ Foscari University, Venice, Italy. UL: Department of Statistics, prey foraging activity patterns match? A study of coyotes (Canis latrans), and lagomorphs (Lepus californicus and Sylvilagus audobonii). Journal of Arid Activity patterns of urban red foxes (Vulpes vulpes) reduce the risk of trafficinduced mortality. Behavioral Ecology, 18(4), 716-724. 
498 Barrientos, R., \& Virgós, E. (2006). Reduction of potential food interference in two

499 sympatric carnivores by sequential use of shared resources. Acta Oecologica, 30(1),

$500 \quad 107-116$.

501

502

503

504
Barrull, J., Mate, I., Ruiz-Olmo, J., Casanovas, J. G., Gosàlbez, J., \& Salicrú, M. (2014). Factors and mechanisms that explain coexistence in a Mediterranean carnivore assemblage: an integrated study based on camera trapping and diet. Mammalian Biology, 79(2), 123-131.

Batschelet, E. (1981). Circular statistics in biology. New York: Academic Press.

Bennie, J. J., Duffy, J. P., Inger, R., \& Gaston, K. J. (2014). Biogeography of time partitioning in mammals. Proceedings of the National Academy of Sciences of the United States of America, 111(38), 13727-13732.

Brashares, J. S., Prugh, L. R., Stoner, C. J., \& Epps, C. W. (2010). Ecological and conservation implications of mesopredator release. In Trophic cascades: predators, prey, and the changing dynamics of nature (pp. 221-240).

Camps, D. (2008). Activity patterns of adult common genets Genetta genetta (Linnaeus, 1758) in northeastern Spain. Galemys, 20(1), 47-60.

Cavallini, P., \& Lovari, S. (1994). Home range, habitat selection and activity of the red fox in a Mediterranean coastal ecotone. Acta Theriologica, 39(3), 279-287.

Chesson, P. (2000). Mechanisms of maintenance of species diversity. Annual Review of Ecology and Systematics, 31(1), 343-366. 
518 Davis, M. L., Kelly, M. J., \& Stauffer, D. F. (2011). Carnivore co $\square$ existence and habitat

519 use in the Mountain Pine Ridge Forest Reserve, Belize. Animal Conservation,

$520 \quad 14(1), 56-65$.

521 Dellafiore, C. M., Rouco, C., Vallés, S. M., \& Fernández, J. B. G. (2014). Seasonal habitat use by the European rabbit (Oryctolagus cuniculus) in a coastal dune system in SW Spain. Animal Biodiversity and Conservation, 2, 233-242.

Di Bitetti, M. S., Di Blanco, Y. E., Pereira, J. A., Paviolo, A., \& Pírez, I. J. (2009). Time Partitioning Favors the Coexistence of Sympatric Crab-Eating Foxes (Cerdocyon thous) and Pampas Foxes (Lycalopex gymnocercus). Journal of Mammalogy, 90(2), Drivers of red fox (Vulpes vulpes) daily activity: prey availability, human disturbance or habitat structure? Journal of Zoology, 298(2), 128-138. North American elk (Cervus elaphus): Indication for a weak circadian clock in ungulates. PLoS ONE, 9(9), e106997. Nacional de Doñana. Doñana Acta Vertebrata, 23(2), 143-152. badger, Meles meles, to a decline of its main prey in the Donana National Park. Journal of Zoology, 245(2), 214-128. 
540 Fedriani, J. M., Palomares, F., \& Delibes, M. (1999). Niche relations among three sympatric Mediterranean carnivores. Oecologia, 121(1), 138-148.

Fenn, M. G. P., \& Macdonald, D. W. (1995). Use of middens by red foxes: risk reverses rhythms of rats. Journal of Mammalogy, 76(1), 130-136. mammalian carnivores to a sudden collapse of rabbits in Mediterranean Spain. Basic and Applied Ecology, 12(2), 116-124. Silveira, L. (2013). Jaguar and puma activity patterns and predator $\square$ prey interactions in four Brazilian biomes. Biotropica, 45(3), 373-379. of human disturbance on wildlife nocturnality. Science, 360(6394), 1232-1235. systems with exploitative and apparent competition. The American Naturalist, Domínguez, F., ... López-Bao, J. V. (2019). Restoring apex predators can reduce mesopredator abundances. Biological Conservation, 238, 108234. 
561 Lê, S., Josse, J., \& Husson, F. (2008). \{FactoMineR \}: A Package for Multivariate

$562 \quad$ Analysis. Journal of Statistical Software, 25(1), 1-18.

563 Lima, S. L., \& Bednekoff, P. A. (1999). Temporal variation in danger drives

564 antipredator behavior: the predation risk allocation hypothesis. The American

$565 \quad$ Naturalist, 153(6), 649-659.

566 Linkie, M., \& Ridout, M. S. (2011). Assessing tiger-prey interactions in Sumatran

567 rainforests. Journal of Zoology, 284(3), 224-229.

568 Lode, T. (1995). Activity pattern of polecats Mustela putorius L. in relation to food 569 habits and prey activity. Ethology, 100(4), 295-308.

MacArthur, R. H., \& Pianka, E. R. (1966). On optimal use of a patchy environment. The American Naturalist, 100(916), 603-609.

Maloney, S. K., Moss, G., Cartmell, T., \& Mitchell, D. (2005). Alteration in diel activity patterns as a thermoregulatory strategy in black wildebeest (Connochaetes gnou). Journal of Comparative Physiology A, 191(11), 1055-1064. badgers (Meles meles) in a Mediterranean environment. Oecologia, 101(1), 45-50. patterns of mammalian prey and predators. Ethology, 119(12), 1044-1056. 
582 Monterroso, P., Díaz $\square$ Ruíz, F., Lukacs, P. M., Alves, P. C., \& Ferreras, P. (2020).

$583 \quad$ Ecological traits and the spatial structure of competitive coexistence among carnivores. Ecology, 101(8), e03059. regulating the presence of wild rabbit in the National Park of Peneda-Gerês, Portugal. European Journal of Wildlife Research, 50(1), 1-6.

Newsome, T. M., Greenville, A. C., Ćirović, D., Dickman, C. R., Johnson, C. N., Krofel, M., ... Wirsing, A. J. (2017). Top predators constrain mesopredator distributions. Nature Communications, 8, 15469.

Palomares, F. (1993). Opportunistic feeding of the Egyptian mongoose, Herpertes

Palomares, F., \& Caro, T. M. (1999). Interspecific killing among mammalian carnivores. ichneumon y de la gineta Genetta genetta en la Reserva Biológica de Doñana, SO de la Península Ibérica. Doñana Acta Vertebrata, 18(1), 5-20. 
603

604

605

606

607

608

609

610

611

612

(SO de la Península Ibérica). Boletín de La Real Sociedad Española de Historia Natural (Sección Biología), 87(1-4), 257-266.

Palomares, F., \& Delibes, M. (1992). Circadian Activity Patterns of Free-Ranging Large Gray Mongooses, Herpestes ichneumon, in Southwestern Spain. Journal of Mammalogy, 73(1), 173-177.

Palomares, F., \& Delibes, M. (1994). Spatio-temporal ecology and behavior of European genets in southwestern Spain. Journal of Mammalogy, 75(3), 714-724.

Palomares, F., Ferreras, P., Fedriani, J. M., \& Delibes, M. (1996). Spatial relationships between Iberian lynx and other carnivores in an area of south-western Spain. Journal of Applied Ecology, 33, 5-13.

Palomares, F., Ferreras, P., Travaini, A., \& Delibes, M. (1998). Co-existence between Iberian lynx and Egyptian mongooses: estimating interaction strength by structural equation modelling and testing by an observational study. Journal of Animal Ecology, 67(6), 967-978.

Polis, G. A., Myers, C. A., \& Holt, R. D. (1989). The ecology and evolution of intraguild predation: potential competitors that eat each other. Annual Review of Ecology and Systematics, 20(1), 297-330.

Prugh, L. R., Stoner, C. J., Epps, C. W., Bean, W. T., Ripple, W. J., Laliberte, A. S., \& Brashares, J. S. (2009). The rise of the mesopredator. Bioscience, 59(9), 779-791.

Pyke, G. H., Pulliam, H. R., \& Charnov, E. L. (1977). Optimal foraging: a selective review of theory and tests. The Quarterly Review of Biology, 52(2), 137-154. 
$624 \quad$ R Core Team. (2020). R: A Language and Environment for Statistical Computing.

625

626

627

628

629

630

631

632
Vienna, Austria: R Foundation for Statistical Computing. Retrieved from https://www.r-project.org/

Rao, J. S. (1976). Some tests based on arc-lengths for the circle. Sankhyā: The Indian Journal of Statistics, Series B, 329-338.

Rau, J. R. (1987). Ecología del zorro," Vulpes vulpes (L.)", en la reserva biológica de Doñana, SO de España. Universidad de Sevilla.

Revilla, E., \& Palomares, F. (2002). Does local feeding specialization exist in Eurasian badgers? Canadian Journal of Zoology, 80(1), 83-93.

Ridout, M. S., \& Linkie, M. (2009). Estimating overlap of daily activity patterns from camera trap data. Journal of Agricultural, Biological, and Environmental Statistics, 14(3), 322-337.

Rodríguez, A., Martin, R., \& Delibes, M. (1996). Space use and activity in a Mediterranean population of badgers Meles meles. Acta Theriologica, 41, 59-72.

Rowcliffe, J. M., Kays, R., Kranstauber, B., Carbone, C., \& Jansen, P. A. (2014). Quantifying levels of animal activity using camera trap data. Methods in Ecology and Evolution, 5(11), 1170-1179.

Rowcliffe, M. (2019). activity: Animal Activity Statistics. Retrieved from https://cran.rproject.org/package=activity

Santos, F., Carbone, C., Wearn, O. R., Rowcliffe, J. M., Espinosa, S., Lima, M. G. M., ... Alvarez-Loayza, P. (2019). Prey availability and temporal partitioning modulate felid coexistence in Neotropical forests. PloS One, 14(3), e0213671. 
646 Schoener, T. W. (1974). The compression hypothesis and temporal resource partitioning. Proceedings of the National Academy of Sciences of the United States of America, 71(10), 4169-4172. homogeneous Mediterranean landscapes: functional importance of habitat segregation at the fine-scale level. Oecologia, 179(1), 223-235. Reconstructed Dynamics of Rapid Extinctions of Chaparral $\square$ Requiring Birds in Urban Habitat Islands. Conservation Biology, 2(1), 75-92.

Terborgh, J., Holt, R. D., \& Estes, J. (2010). Trophic cascades: what they are, how they work, and why they matter. In Trophic Cascades: Predators, Prey and the temminck. Terre et Vie (Revue d'Ecologie), 104, 51-67. Mammals. Biotropica, 28(1), 105-112. 
667 Vilella, M., Ferrandiz $\square$ Rovira, M., \& Sayol, F. (2020). Coexistence of predators in time: Effects of season and prey availability on species activity within a Mediterranean carnivore guild. Ecology and Evolution, 00, 1-15. influencing the seasonal daily activity of the European rabbit (Oryctolagus cuniculus) in a Mediterranean area. Mammalia, 57(3), 341-347. genetta L.) diet: a literature review. Mammal Review, 29(2), 117-126. 


\section{Figures}

687 Figure 1. Niche segregation along the trophic axis among mesocarnivores in Doñana

688 National Park. The first two CA dimensions (Dim 1, Dim 2) explain 66\% of the variability in

689 diet composition between species and studies. The first dimension represents a gradient of

690 diet variability between the common genet and the European badger, while the second

691 dimension separates the diet of the red fox and the common genet. Convex polygons

692 represent trophic niche breadth.

693 Figure 2. Pairwise comparisons of daily activity patterns between mesocarnivores (rows, top

694 to bottom: red fox, badger, genet, and Egyptian mongoose) and their main prey items in the

695 study area (columns, left to right: Oryctolagus cunniculus, small mammals, and Alectoris

$696 r u f a$ ). Coloured lines describe prey activity patterns (blue for European rabbit, green for small

697 mammals and yellow for red-legged partridge) and black lines indicate predator's activity

698 patterns. Overlap coefficients $(\Delta)$ and their respective $99 \%$ confidence intervals are shown in

699 brackets.

700 Figure 3. Diel activity patterns of two mesocarnivores (red fox and Egyptian mongoose; mid

701 and bottom rows, respectively) and its main prey item (European rabbit, top row) along the

702 gradient of ecological succession, from younger juniper stands (SABCOL) to mature, late

703 successional stands (SABMAR).

704 Figure 4. Kernel density plots and temporal overlap between mesocarnivores in the study

705 area: common genet (green line), red fox (blue line), European badger (purple line) and

706 Egyptian mongoose (yellow line). Overlap coefficients $(\Delta)$ and their respective $99 \%$

707 confidence intervals are shown in brackets. 


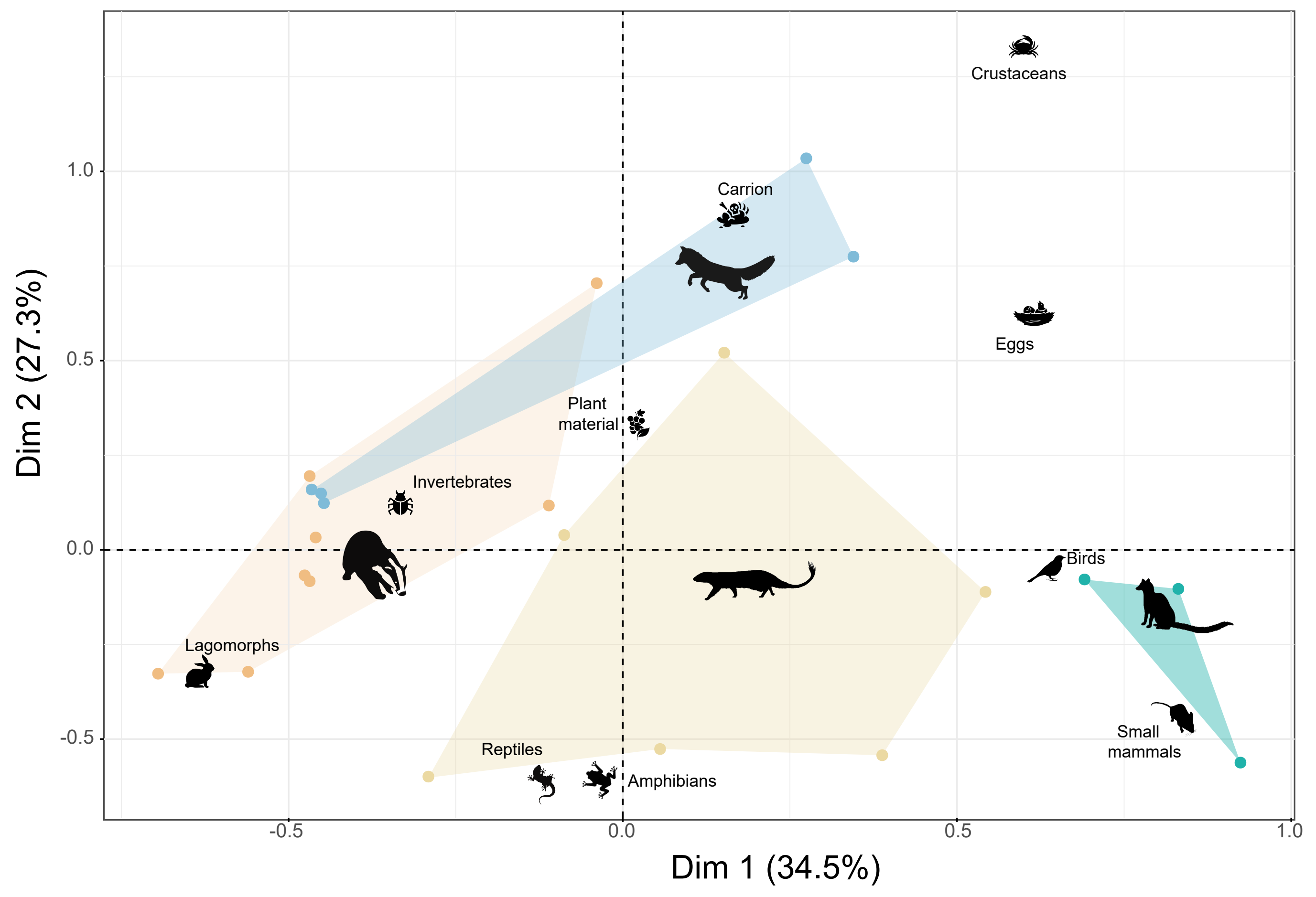




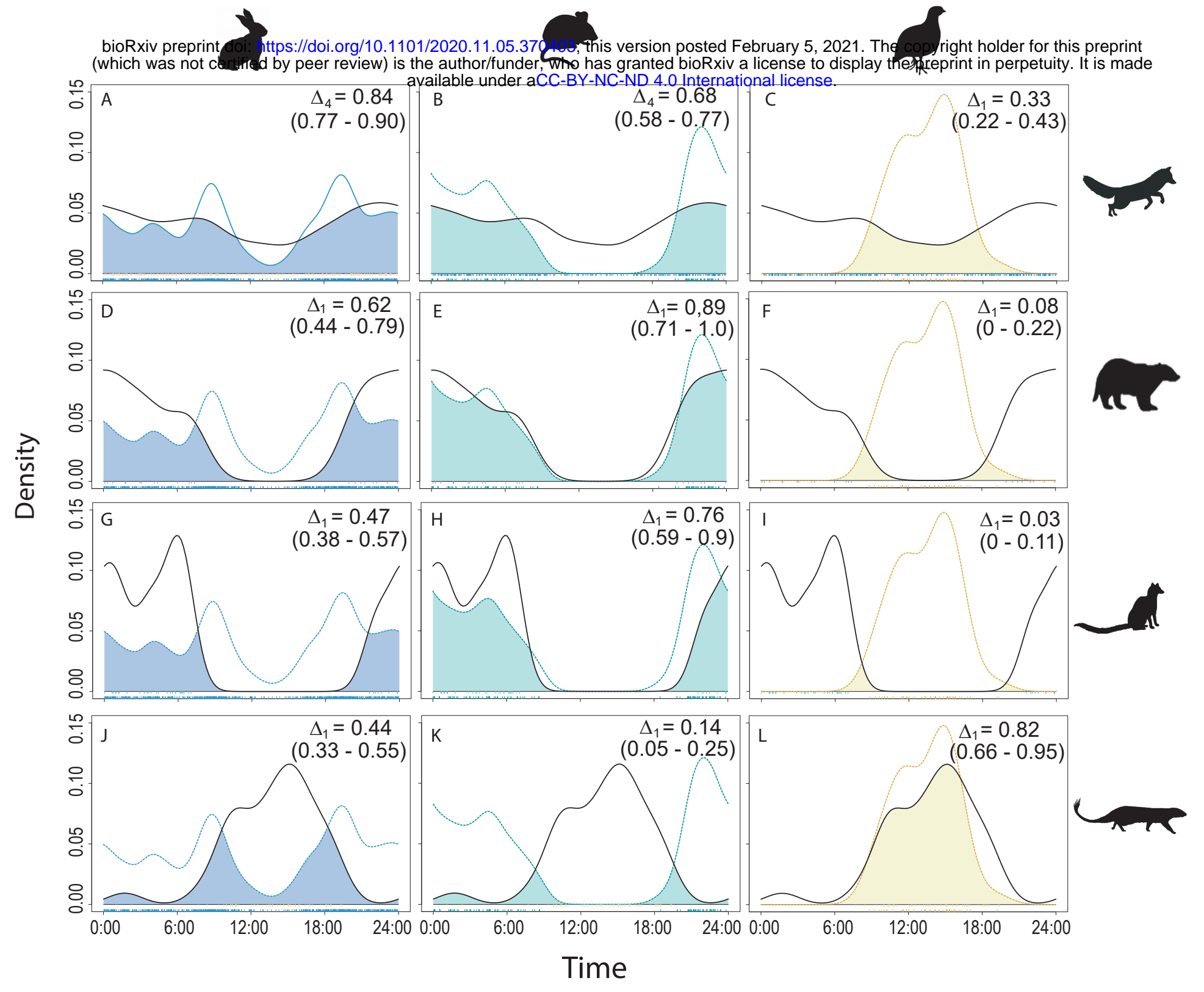


Landscape maturity
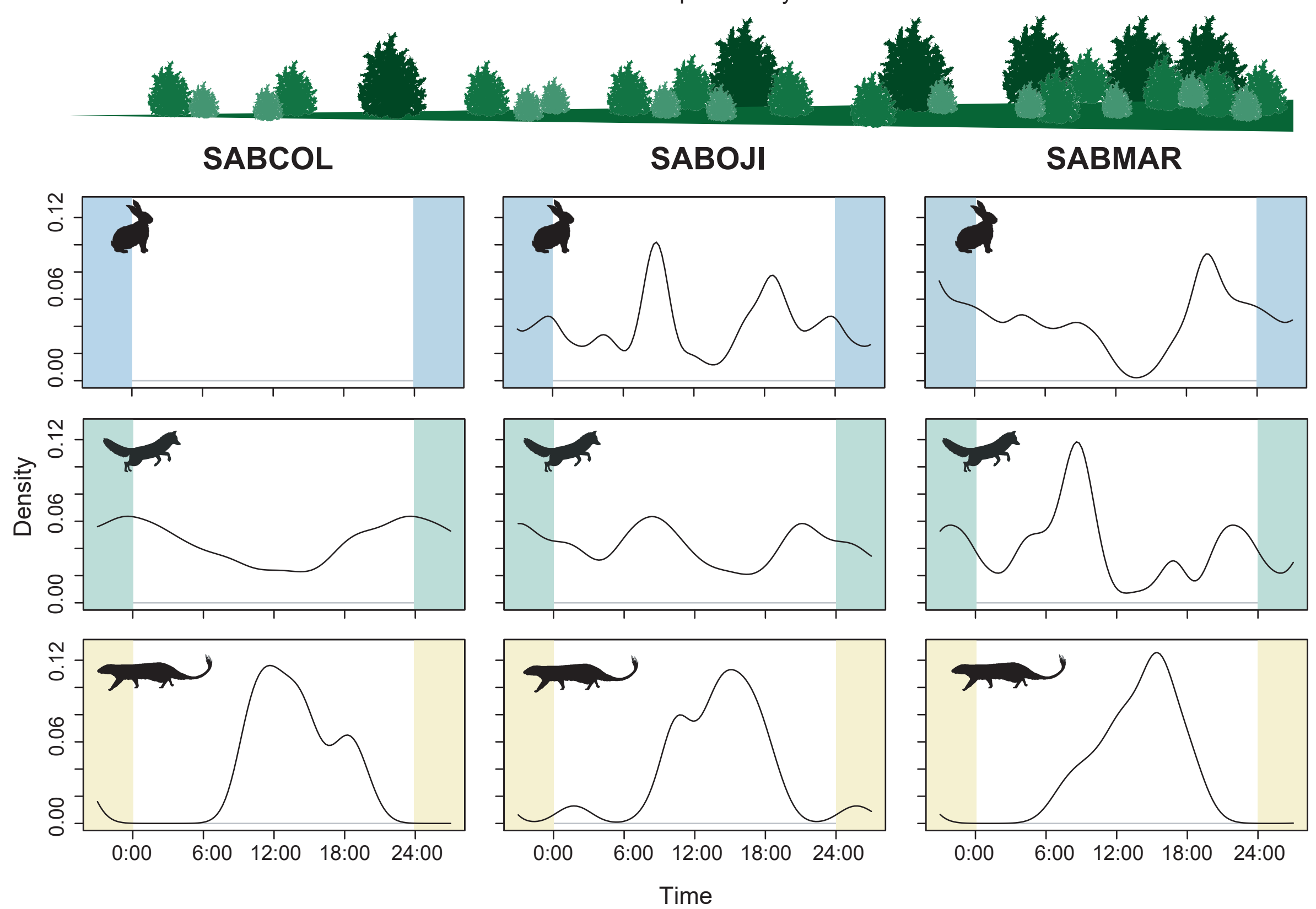
bioRxiv preprint doi: https://doi.org/10.1101/2020.11.05.370403; this version posted February 5, 2021. The copyright holder for this preprint (which was not certified by peer review) is the author/funder, who has granted bioRxiv a license to display the preprint in perpetuity. It is made


Time 